\title{
Validation of internal reference genes for quantitative real-time PCR in a non-model organism, the yellow-necked mouse, Apodemus flavicollis
}

\author{
Jan Axtner and Simone Sommer*
}

\author{
Address: Leibniz Institute for Zoo and Wildlife Research (IZW), Evolutionary Genetics, Alfred-Kowalke-Strasse 1710315 Berlin, Germany \\ Email: Jan Axtner - axtner@izw-berlin.de; Simone Sommer* - sommer@izw-berlin.de \\ * Corresponding author
}

Published: 23 December 2009

BMC Research Notes 2009, 2:264 doi:10.1186/1756-0500-2-264

This article is available from: http://www.biomedcentral.com/1756-0500/2/264

(c) 2009 Sommer et al; licensee BioMed Central Ltd.

This is an Open Access article distributed under the terms of the Creative Commons Attribution License (http://creativecommons.org/licenses/by/2.0), which permits unrestricted use, distribution, and reproduction in any medium, provided the original work is properly cited.

\begin{abstract}
Background: Reference genes are used as internal standards to normalize mRNA abundance in quantitative real-time PCR and thereby allow a direct comparison between samples. So far most of these expression studies used human or classical laboratory model species whereas studies on nonmodel organism under in-situ conditions are quite rare. However, only studies in free-ranging populations can reveal the effects of natural selection on the expression levels of functional important genes. In order to test the feasibility of gene expression studies in wildlife samples we transferred and validated potential reference genes that were developed for lab mice (Mus musculus) to samples of wild yellow-necked mice, Apodemus flavicollis. The stability and suitability of eight potential reference genes was accessed by the programs BestKeeper, NormFinder and geNorm.
\end{abstract}

Findings: Although the three programs used different algorithms the ranking order of reference genes was significantly concordant and geNorm differed in only one, NormFinder in two positions compared to BestKeeper. The genes ordered by their mean rank from the most to the least stable gene were: Rps /8, Sdha, Canx, Actgl, Pgkl, Ubc, Rpl/3a and Actb. Analyses of the normalization factor revealed best results when the five most stable genes were included for normalization.

Discussion: We established a SYBR green GPCR assay for liver samples of wild A. flavicollis and conclude that five genes should be used for appropriate normalization. Our study provides the basis to investigate differential expression of genes under selection under natural selection conditions in liver samples of $A$. flavicollis. This approach might also be applicable to other non-model organisms.

\section{Background}

Quantitative real-time RT PCR (qPCR) has become a tool with a broad spectrum of use in molecular biology [1]. By quantifying mRNA levels it allows valuable insights into the variation of gene expression between certain individuals or different treatment groups. The most common practice in qPCR is the relative measurement of the expression of a gene of interest after normalization to an internal reference gene. These formerly called house-keeping genes were thought to be constantly expressed in every cell or every tissue and were supposed to be neither up nor down regulated. This assumption has proven false by a growing number of studies [2-4]. All genes seem to be regulated under some conditions and there seems to be no universal 
reference gene with a constant expression in all tissues [59]. But still the relative quantification against an internal reference gene is the most accurate way to detect expression differences especially in low copy mRNA because it controls for artificial variation, e.g. due to differences in the amount of sample, RNA extraction or reverse transcription efficiency [10]. Thus, a careful validation of the usefulness of potential reference genes is highly recommended [1,6,10-15] but not always applied [16]. So far gene expression studies and therefore also reference gene validations are mainly limited to human or classical laboratory organisms as non-model species often suffer from the lack of background information available. For example the real-time PCR primer data base RTPrimerDB [17] includes 5319 primer sets for animals and humans, whereof 3992 were designed for humans followed by 805 for mice (Mus musculus) and 454 for rats (Rattus norvegicus) commonly used in labs. But particularly non-model species are of great interest to evolutionary genetics or ecologists as classical model species might be poor reflections of wildlife which face the constantly changing and challenging conditions of their natural environment [18]. Focusing just on model species could mean working on the expense of ecological and evolutionary realism and insitu studies on wild populations are required to account for natural selection conditions.

In this study we established a SYBR green qPCR assay for liver samples obtained from wild caught Apodemus flavicollis. The yellow-necked mouse is a common European murid in deciduous and mixed forests. It belongs to the subfamily Murinae [19] and has been subject to a broad range of genetic, ecological, evolutionary and parasitological studies [20-25]. Especially host-parasite interactions are of special interest in this species as this species serve as one of the main reservoir for vector-borne diseases agents (e.g. Salmonella spp., Borreliosis or Hanta virus infections) in Central Europe [25]. The results of our study are the prerequisite to investigate the adaptive variance of expression levels of immune genes, specifically major histocompatibility complex class II genes, in relation to individual pathogen burden to test the hypothesis that in a natural environment not only structural sequence variation but also differential expression of adaptive genes is under selection. Therefore, we validated eight potential reference genes from a panel of primer sets that were originally designed for Mus musculus and tested their application for relative gene expression analysis in A. flavicollis.

\section{Results and discussion \\ Potential reference genes}

All 15 tested reference gene primer sets were originally designed for Mus musculus (Table 1). It turned out that none of the six primer sets from the RTPrimer data base [17] nor the primers for the reference gene $B 2 \mathrm{~m}$ of the Mouse Normalisation Gene Panel (Quantace) did amplify a product in the related non-model species Apodemus flavicollis. Transferring primer sets from closely related organisms limits the set of genes that are tested and might reduce the chance to find a good internal reference as the possible choice depends on the set and number of genes that were used. However, eight intron spanning primer sets of the Mouse Normalisation Gene Panel (Quantace) performed well in A. flavicollis, which still is a comparable

Table I: Names, function, database ID and annealing temperature (Ta) of the tested primer sets

\begin{tabular}{|c|c|c|c|c|}
\hline Abbreviation & Gene & Function & Accession Number & $\mathbf{T}_{\mathrm{a}}\left[{ }^{\circ} \mathbf{C}\right]$ \\
\hline Actb-I & actin, beta & cytoskeletal structural protein & $2848 \#$ & $60^{\circ} \mathrm{C}$ \\
\hline Actb-2 & actin, beta & involved in cell motility, structure and integrity & ensmusg00000029580+ & $55^{\circ} \mathrm{C}$ \\
\hline Actgl & actin, gamma, cytoplasmicl & Cytoskeletal structural protein & ensmusg00000062825+ & $55^{\circ} \mathrm{C}$ \\
\hline B2 m-I & beta-2 microglobulin & cytoskeletal protein involved in cell locomotion & $3584 \#$ & $60^{\circ} \mathrm{C}$ \\
\hline B2 $\mathrm{m}-2$ & beta-2 microglobulin & cytoskeletal protein involved in cell locomotion & ensmusg00000060802+ & $55^{\circ} \mathrm{C}$ \\
\hline Canx & calnexin & $\begin{array}{l}\text { protein folding and quality control in the } \\
\text { endoplasmic reticulum }\end{array}$ & ensmusg00000020368+ & $55^{\circ} \mathrm{C}$ \\
\hline Gapdh & glyceraldehyde-3-phosphate dehydrogenase & carbohydrate metabolism & 3244\# & $60^{\circ} \mathrm{C}$ \\
\hline Hprtl & $\begin{array}{l}\text { hypoxanthine guanine phosphoribosyl } \\
\text { transferase I }\end{array}$ & metabolic salvage of purines in mammals & $50 \#$ & $55^{\circ} \mathrm{C}$ \\
\hline Pgkl & phosphoglycerate kinase I & transferase enzyme in the glycolysis & ensmusg00000062070+ & $55^{\circ} \mathrm{C}$ \\
\hline Sdha & $\begin{array}{l}\text { succinate dehydrogenase complex, subunit } \\
\text { A }\end{array}$ & tricarboxylic acid cycle & ensmusg00000021577+ & $55^{\circ} \mathrm{C}$ \\
\hline$R p I / 3 a$ & ribosomal protein LI3A & member of ribosome protein & enst00000270634+ & $55^{\circ} \mathrm{C}$ \\
\hline Rplp0 & ribosomal protein, large, $\mathrm{PO}$ & member of ribosome protein & $286 \mid \#$ & $60^{\circ} \mathrm{C}$ \\
\hline Rps I 8 & ribosomal protein SI8 & member of ribosome protein & ensmusg00000008668+ & $55^{\circ} \mathrm{C}$ \\
\hline Tubala & tubulin, alpha IA & structural protein & |484\# & $58^{\circ} \mathrm{C}$ \\
\hline Ubc & Ubiquitin $\mathrm{C}$ & protein degradation & ensmusg00000008348+ & $55^{\circ} \mathrm{C}$ \\
\hline
\end{tabular}

The eight reference genes that performed well in A. flavicollis liver samples are marked in bold.

\# RTPrimerDB: http://medgen.ugent.be/rtprimerdb

+ Ensembl Project: http://www.ensembl.org/index.html; Primer of Gene Normalization Panel 
number to other validation studies [9,26-28]. They amplified conserved parts of the succinate dehydrogenase complex (Sdha), $\gamma$-actin (Actg1), ribosomal protein S18 (Rps18), ribosomal protein L13a (Rpl13a), phosphoglycerate kinase 1 (Pgk1), calnexin (Canx), $\beta$-actin $(A c t b)$ and ubiquitin $\mathrm{C}(U b c)$. Further functions and accession numbers are provided in Table 1. As the sequences of the commercial primer sets were unknown we applied molecular cloning and subsequent sequence analysis using the vector primers T7 and M13 to confirm amplicon identity. The GenBank accession numbers are provided in Table 2. All gene identities could be confirmed but Rpl13a turned out to be not intron spanning. Sequencing revealed that the commercial primer set for RPL13a did amplify part of the small nuclear RNA (sno RNA) U35 that is situated in the sixth intron of Rpl13a and part of the seventh exon of Rpl13a.

\section{Amplification rate}

The average arithmetic mean (AM) of the amplification rate $E$ ranged from 1.82 for Actb to 1.88 for Actg1 (Table 2 ). The coefficient of variance (CV) expresses the variance of the amplification rate between the different qPCR runs. It was 0.05 for all reference genes except for Actg1 and Rps18 (0.06) (Table 2). The lowest $\mathrm{Ct}$-value recorded was 12.87 cycles and the highest was 28.87 cycles. The difference in the $\mathrm{Ct}$-values between the genes within a run ranged from 9.83 cycles to 14.81 cycles (Table 2 ).

\section{Identification of optimal reference genes}

All our analyses on the stability of the references genes using the different algorithms showed consistent results with only slight differences in the ranking order (Table 3). A Kendall's $W$ test showed a very high concordance of gained orders (Kendall's $W=0.958,2=20.108, \mathrm{df}=7, \mathrm{p}$ $<0.01)$. The resulting mean rank order of the genes from low to high variation was Rps18, Sdha, Canx, Actg1, Pgk1, Ubc, Rpl13a and Actb.

\section{BestKeeper analysis}

The software BestKeeper ranked all genes by their Ct-value variance (low to high): Rps18, Sdha, Canx, Pgk1, Actg1, $U b c, R p l 13 a$ and Actb (Table 2). It considers all genes showing a variation in their amount of starting material by the factor two or more as unstable [14]. In an ideal PCR reaction with an amplification rate of two $(100 \%$ reaction efficiency) this would be any gene whose Ct-values show a standard deviation $S D_{\text {Ct-value }}>1$, which is used as default by BestKeeper. Hibbeler $e t$ al. [8] already ruled out that the default setting of BestKeeper might be a too strict rule and limits its use to a very restricted experimental setup. In invivo samples, it is difficult to achieve a $S D_{\text {Ct-value }}<1$ as whole-tissue biopsies usually represent a composition of different cell types and show therefore a higher variation [29]. Additionally in biological samples the reaction efficiency is rarely $100 \%$ [13]. We therefore adjusted the SDthreshold for each gene to its specific efficiency. As a consequence we made BestKeeper more applicable but still rejected every gene whose $S D_{\text {Ct-value }}$ indicated a variation in the starting template by the factor two. According to our study the first four genes could be considered as stable reference genes as the $S D_{\text {Ct-value }}$ was lower than their individual SD-threshold whereas the other genes were considered as unstable (Table 2).

Table 2: Descriptive statistics of the tested reference genes

\begin{tabular}{|c|c|c|c|c|c|c|c|c|}
\hline & Rps /8 & Sdha & Canx & PgkI & ActgI & Ubc & $R p / I 3 a$ & Actb \\
\hline GenBank ID & GU188049 & GUI88053 & GUI8805I & GUI88052 & GUI88050 & GUI88054 & GUI88056 & GUI88055 \\
\hline $\mathrm{AM}_{\text {amplification rate }}$ & 1.86 & 1.88 & 1.83 & 1.85 & 1.88 & 1.86 & 1.85 & 1.82 \\
\hline $\mathrm{CV}_{\text {amplification rate }}$ & 0.06 & 0.05 & 0.05 & 0.05 & 0.06 & 0.05 & 0.05 & 0.05 \\
\hline $\mathbf{G M}_{\mathrm{Ct}_{\text {-value }}}$ & 14.62 & 15.37 & 16.63 & 15.72 & 16.83 & 15.72 & 26.05 & 16.05 \\
\hline$A M_{C t \text {-value }}$ & 14.64 & 15.42 & 16.68 & 15.78 & 16.88 & 15.79 & 26.10 & 16.16 \\
\hline $\mathrm{CV}_{\mathrm{Ct} \text {-value }}$ & 0.04 & 0.07 & 0.07 & 0.07 & 0.07 & 0.08 & 0.06 & 0.09 \\
\hline Minimum $_{\mathrm{Ct} \text {-value }}$ & 13.86 & 13.90 & 14.65 & 13.42 & 14.94 & 12.87 & 24.30 & 13.64 \\
\hline Maximum $_{\text {Ct-value }}$ & 16.74 & 17.68 & 19.61 & 18.62 & 19.68 & 18.26 & 28.87 & 20.50 \\
\hline$S D_{\text {Ct-value }}$ & 0.65 & 1.09 & 1.09 & 1.10 & 1.11 & 1.26 & 1.45 & 1.49 \\
\hline SD-threshold & 1.12 & 1.10 & 1.15 & 1.13 & 1.10 & 1.12 & 1.13 & 1.16 \\
\hline Minimum [x-fold] & -1.60 & -2.52 & -3.30 & -4.10 & -3.29 & -5.90 & -2.94 & -4.24 \\
\hline Maximum [x-fold] & 3.71 & 4.27 & 6.10 & 5.93 & 6.00 & 4.84 & 5.65 & 14.49 \\
\hline$S D[ \pm x$-fold $]$ & 1.50 & 1.99 & 1.99 & 2.00 & 2.01 & 2.21 & 2.49 & 2.56 \\
\hline
\end{tabular}

Arithmetic mean (AM), geometric mean (GM), coefficient of variance (CV) and standard deviation (SD) of the amplification rate $E$ and the $C t-v a l u e s$ for every potential reference gene. The genes are ordered by their $S D_{C \text { tvalue }}$. Genes that showed a $S D_{C t \text {-value }}$ smaller than the $S D$-threshold are considered to be suitable reference genes and marked in bold. The last three rows show the maximum and minimum values of the over- and underexpression of a gene in relation to its calculated geometric mean (displayed as $\mathbf{x}$-fold ratio) as well as the standard deviation (calculated with BestKeeper). 
Table 3: Ranking order of the reference genes obtained by the three used algorithms implemented in BestKeeper, NormFinder and geNorm.

\begin{tabular}{lllllllll}
\hline & RpsI8 & Sdha & Canx & PgkI & ActgI & Ubc & RpII3a & Actb \\
\hline $\begin{array}{l}\text { BestKeeper } \\
\text { NormFinder }\end{array}$ & 1 & 2 & 3 & 4 & 5 & 6 & 7 & 8 \\
geNorm & 2 & 1 & 3 & 4 & 5 & 7 & 6 & 7 \\
\hline mean rank & 1.5 & 3 & 1.5 & 4 & 5 & 6 & 8 \\
\hline
\end{tabular}

\section{NormFinder analysis}

The ranking of the computer program NormFinder [12] is not based on the Ct-values but on the expression values. Compared to the BestKeeper ranking only two changes at the first and the sixth position occurred: Sdha $(<0.382$, Fig. 1 ) changed place with $R p s 18<0.427)$ and was the most stable gene while Rpl13a $(<0.734)$ changed place with $U b c$ (>0.771) and became the sixth most stable gene. However, the five most stable genes differ only by just 0.084 points in their stability values, while the difference among the last three genes is more than three times larger than this (Fig. 1).

\section{geNorm analysis}

The program geNorm [6] ranks the potential reference genes due to their average pairwise variation in expression of one gene compared to each other gene of the set. It is independent of inter-run variability or different reverse transcription RT efficiencies. Only one change occurred compared to the ranking of BestKeeper: Canx becomes together with Rps18 one of the two most stable genes,

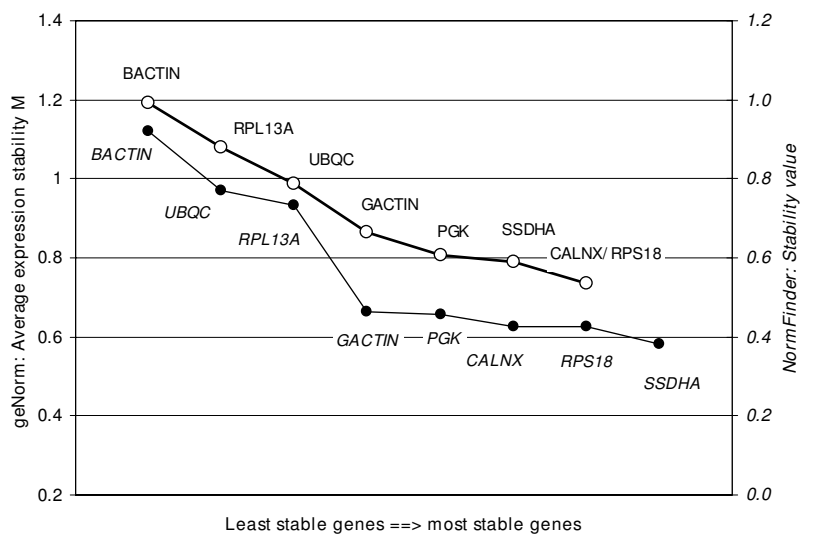

Figure I

Gene expression stability values of the eight potential reference genes. The stability values on the right axis were calculated with NormFinder [12] (black circles) and the average expression stability values $M$ (white circles) on the left axis were calculated with geNorm [6] after stepwise exclusion of the least stable gene. Genes are plotted from the least to the most stable expressed genes. which cannot be further ranked $\left(\mathrm{M}_{\mathrm{Canx} / \mathrm{Rps} 18}=0.73\right)$ (Fig. $1)$. Whereas geNorm is susceptible to identify co-regulated genes as optimal reference genes as they would show a constant ratio, NormFinder and BestKeeper do not suffer from this problem. As all three softwares produce consistent results we assume that the potential problem of coregulated genes does not apply to our data.

\section{Number of reference genes}

The use of just a single reference gene may result in a more than 6-fold erroneous normalization [6] and it is therefore recommended to use more than one reference gene $[1,30]$ and calculate a normalization factor (NF) $[6,14]$. As Vandesompele et al. [6] pointed out it is a trade off between accuracy and feasibility, but it seems inappropriate if the number of reference genes exceeds the number of genes of interest by far. To find the optimal number of reference genes for normalization geNorm calculates whether the stepwise inclusion of a less stable gene into the normalization factor $N F_{n}$ affects the variance $V_{n / n+1}$ compared $N F_{n+1}$ (Fig. 2). We observed the lowest Variation $V_{n / n+1}$ between inclusion of the fourth and fifth most stable reference gene $\left(V_{4 / 5}=0.164\right)$ (Fig. 2). A high $V_{n / n+1}$ means that the inclusion of the next gene had a big effect and it still should be included into the calculation of an accurate NF. $V_{4 / 5}=0.164$ is a bit higher than the cut off value of 0.15 suggested by Vandesompele et al. [6]. But this is an empirical value and should not be taken as a too strict cut off value, as it is already suggested by the geNorm manual itself. Although Actg1 was refused as a reference gene by BestKeeper analysis we would suggest to use the first five reference genes Rps18, Canx, Sdha, Pgk1 and Actg1 for calculating a NF in A. flavicollis, as Actg1 only slightly missed the SD-threshold. This is further supported by the results of NormFinder as we observed a clear increase of the stability value between the fifth and the sixth most stable gene. This increase is more then three times as high as the over-all difference between the first and the fifth gene. This shows that the first five genes are much more similar in expression stability than the last three ones.

\section{Conclusions}

Although we expected higher expression variability due to more heterogeneity in terms of age or physiological stages 


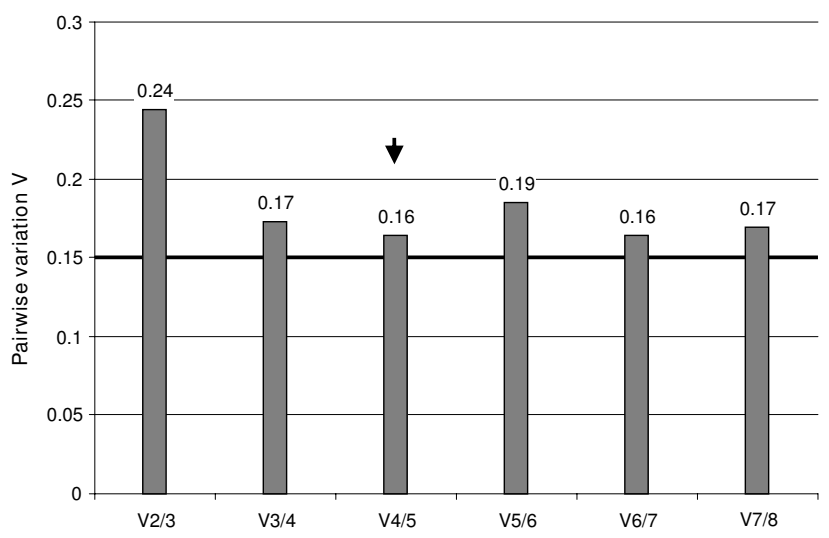

Figure 2

Pairwise variation $V_{n / n+1}$ between the normalizing factors $N F_{n}$ and $N F_{n+1}$ The variation $V_{n / n+1}$ between $N F_{n}$ and $N F_{n+1}$ was calculated with geNorm to determine the optimal number of reference genes that should be used for normalization. The empirical cut-off value 0.15 defined by Vandensompele et al. [6] is marked by a thick line. The lowest variability is marked with an arrow.

in our samples we could show that relative quantification via real-time PCR is feasible in samples from wild caught animals. The five genes Rps18, Canx, Sdha, Pgk1 and Actg1 were most stable and should allow an appropriate normalization factor for accurate measurement. We hope that our study will encourage other researchers to apply qPCR in eco-genomic studies on other wildlife species.

\section{Methods}

\section{Sample collection}

We live trapped wild yellow necked mice (Apodemus flavicollis) in 2007/08 in a deciduous forest about $35 \mathrm{~km}$ north-east of Hamburg, Germany. Mice were anesthetized by inhalation of isoflurane (Forene ${ }^{\odot}$ ) and then sacrificed immediately by cervical dislocation at the trapping site. Liver samples were taken and stored in RNA-Later (Sigma), kept at $4{ }^{\circ} \mathrm{C}$ for $24 \mathrm{~h}$ and then frozen at $-20^{\circ} \mathrm{C}$ until further treatment.

\section{RNA extraction and cDNA synthesis}

Thirty mg liver tissue of 14 animals were placed in tubes with $500 \mu \mathrm{l}$ of QIAzol lyses reagent (Qiagen) with $1.4 \mathrm{~mm}$ ceramic beads. Tissue was disrupted in a homogenizer (Precellys, Bertin Technologies) $(2 \times 10 \mathrm{~s}$ at $5000 \mathrm{rpm})$ and total RNA was extracted following the QIAzol lyses reagent protocol and dissolved in $87.5 \mu \mathrm{l}$ of water. A DNA digestion with DNase I (RNase-free DNase Kit, Qiagen) and a subsequent clean-up via RNeasy spin columns (Qiagen) according to the manufacturer's protocol was done. Total RNA was finally eluted in $60 \mu \mathrm{l}$ of water and its amount and purity was assessed with the Nanodrop 1000
(Thermo Scientific) three times and averaged. Two $\mu \mathrm{g}$ of total RNA were reverse transcribed with Oligo- $\mathrm{dT}_{18}$ primers $(5 \mu \mathrm{M})$. Reverse transcription was run in triplicates of $40 \mu \mathrm{l}$ using the SensiMix two step kit (Quantace) according to the manufacturer's protocol. All RT-triplicates were mixed and the copied cDNA was diluted 1:16 prior qPCR with aqua dest.

\section{Primer selection}

We chose six rodents primer sets out of the RTPrimer data base because they potentially amplified reference genes with similar length and identical annealing temperature $T_{a}$. We also tested nine intron spanning primer sets out of the commercially available Mouse Normalisation Gene Panel (Quantace) (Table 1). All these potential reference gene primer sets were originally designed for the model organism Mus musculus and we applied them to our nonmodel organism A. flavicollis.

\section{Quantitative real-time RT PCR}

SYBR green qPCR was performed with SensiMix two step kit (Quantace) in a $25 \mu$ l volume on a Rotor Gene 3000 (Corbett Research). All qPCR reactions were run in triplicates with a no-template control to check for contaminations. Each tube contained $4 \mu \mathrm{l}$ of cDNA template, $12.5 \mu \mathrm{l}$ SensiMix dT (Quantace), $0.5 \mu$ l SYBR Green solution, 0.5 $\mu \mathrm{l}$ primer $(50 \mu \mathrm{M})$ and $7.5 \mu \mathrm{dH}_{2} \mathrm{O}$. The qPCR conditions were $10 \mathrm{~min}$ at $95^{\circ} \mathrm{C}$ and 45 cycles of each $95^{\circ}$ for $15 \mathrm{~s}$, $55^{\circ} \mathrm{C}$ for $20 \mathrm{~s}$ and $72^{\circ} \mathrm{C}$ for $20 \mathrm{~s}$. Melting curve analysis was performed from $65^{\circ}$ to $95^{\circ} \mathrm{C}$ in $0.5^{\circ} \mathrm{C}$ steps each lasting $5 \mathrm{~s}$ to confirm presence of a single product and absence of primer-dimers. The individual amplification rate $E$ for every single reaction tube was determined by the 'comparative quantification' function (Corbett Software 6.1.81) to avoid inter-run variation. $E$ is defined as the average increase of fluorescence in the raw data for five cycles following the 'Takeoff value. This Takeoff value is specified as the time at which the second derivative of the raw data is at $20 \%$ of its maximum (Corbett Software 6.1.81). This point marks the end of the background noise and indicates the transition into the exponential phase of the reaction. E was averaged for each gene out of the three replicates in each run. To normalize the raw data the individual background fluorescence from cycle one to the Takeoff value was averaged and all data points of a sample were divided by this average background level ('Dynamic Tube' function, Corbett Software 6.1.81). Individual threshold cycle values (Ct-values) were obtained by setting a threshold manually at 0.01 of the normalized fluorescence ignoring the first five cycles. The Ct-values for a gene were averaged for the three replicates in each run. We 
calculated the expression of each gene arbitrarily as $Q=E^{-}$ $C t$. Note that $Q$ is not the real amount of DNA copies $N_{t}=$ $N_{0}{ }^{*} E^{t}$ to a time point $\mathrm{t}$ but rather the fluorescence that is measured proportional to $N_{t}$. As we set a certain fluorescence threshold we set $N_{Y, C t_{Y}}=N_{X, C t_{X}}$. With the known $E$ and the Ct-value the ratio between two genes depends only upon their start amount of $\mathrm{CDNA} \mathrm{N}_{0}$.

\section{Determination of reference gene expression stability}

The stability of the selected reference genes was determined by BestKeeper [21], NormFinder [18] and geNorm [12]. Concordance between their different ranking orders was tested with Kendall's W implemented in SPSS 16.0.2.

BestKeeper ranks the reference genes by the variation of their Ct-values. The gene with the lowest standard deviation $\left(\mathrm{SD}_{\mathrm{Ct} \text {-value }}\right)$ is proposed to be the most suitable reference gene. Like BestKeeper, we excluded every gene showing a $\mathrm{SD}_{\mathrm{Ct} \text {-value }}$ that would result in a variation of the starting material by the factor two. But unlike BestKeeper, we calculated this SD-threshold for each gene based on its known over-all run average $E: S D_{\text {threshold }}=\frac{\ln 2}{\ln E}$.

NormFinder [18] instead uses a model based approach to analyse the variance in the expression data. It allows for intra- and intergroup variation which makes it more robust against co-expressed genes. In this experiment it was not necessary to distinguish between intra- and intergroup variation as we had only one group of samples. NormFinder calculates a stability value for each gene and the gene with the lowest value is supposed to be the most stable out of the tested set of genes.

GeNorm [12] bases on the simple assumption that expression of two ideal reference genes will always have the same ratio among samples regardless of the experimental conditions before the real-time PCR. The ratio between two genes $(Y$ and $X)$ in a sample is $\frac{Q Y}{Q_{X}}=\frac{E_{y}{ }^{-C t_{Y}}}{E_{X}{ }^{-C t_{X}}}$. The average expression stability value $M$ for each gene is calculated using the expression data. $M$ is the average pairwise variation of a gene compared with each of the other potential reference genes in one sample. The average $M$ of all genes together is then calculated by stepwise exclusion of the least stable gene until the two most stable genes of the set remain that can not be ranked any further.

GeNorm also allows estimating the optimal number of reference genes which should be used for normalization.
It calculates the normalization factor (NF) based on the geometric mean of the expression of more than one reference gene. The more reference genes included in this NF the less possible outliers account. On the other hand using to many genes might include unstable reference genes making it less accurate. GeNorm calculates the $N F_{n}$ for the two most stable reference genes based on the geometric mean of the expression data and then the $N F_{n+1}$ with the next most stable gene. To determine how many genes should be used for accurate normalization the pairwise variation $V_{n / n+1}$ was determined out of two sequential normalization factors $\left(N F_{n}\right.$ and $\left.N F_{n+1}\right)$.

All research reported in this manuscript adhered to the legal requirements of Germany were and complied with the protocols approved by the responsible state office for Agriculture, Environment and Rural Areas of SchleswigHolstein (Referenz No: LANU 315/5327.74.1.6).

\section{Competing interests}

The authors declare that they have no competing interests.

\section{Authors' contributions}

JA performed the sample collection, data acquisition, analysis and interpretation as well as drafting the manuscript. SS was responsible for the overall study design, supervised the study and helped to draft the manuscript. Both authors read and approved the final manuscript.

\section{Acknowledgements}

This study was funded by the Federal Ministry of Education and Research (BMBF). We thank A. Drews, state office for Agriculture, Environment and Rural Areas of Schleswig-Holstein and J. Stäcker, district forester for their support and permission to carry out this study.

\section{References}

I. Bustin SA, Benes V, Nolan T, Pfaffl MW: Quantitative real-time RT-PCR -a perspective. J Mol Endocrinol 2005, 34:597-60I.

2. Selvey S, Thompson EW, Matthaei K, Lea RA, Irving MG, Griffiths LR: $\beta$-Actin -an unsuitable internal control for RT-PCR. Mol Cell Probes 200I, 1 5:307-3 II.

3. Tricarico C, Pinzani P, Bianchi S, Paglierani M, Distante V, Pazzagli M, Bustin SA, Orlando C: Quantitative real-time reverse transcriptionpolymerase chain reaction: normalization to rRNA or single housekeeping genes is inappropriate for human tissue biopsies. Anal Biochem 2002, 309(2):293-300.

4. Bas A, Forsberg G, Hammarström S, Hammarström ML: Utility of the Housekeeping Genes I8S rRNA, $\beta$-Actin and Glyceraldehyde-3-Phosphate-Dehydrogenase for Normalization in Real-Time Quantitative Reverse Transcriptase-Polymerase Chain Reaction Analysis of Gene Expression in Human T Lymphocytes. Scand J Immunol 2004, 59(6):566-573.

5. Thellin O, Zorzi W, Lakaye B, De Borman B, Coumans B, Hennen G, Grisar T, Igout A, Heinen E: Housekeeping genes as internal standards: use and limits. J Biotechnol 1999, 75:29I-295.

6. Vandesompele J, De Preter K, Pattyn F, Poppe B, Van Roy N, De Paepe A, Speleman F: Accurate normalization of real-time quantitative RT-PCR data by geometric averaging of multiple internal control genes. Genome Biol 2002, 3:7.

7. Kouadjo KE, Nishida Y, Cadrin-Girard JF, Yoshioka M, St-Amand J: Housekeeping and tissue-specific genes in mouse tissues. BMC Genomics 2007, 8: 127 . 
8. Hibbeler S, Scharsack JP, Becker S: Housekeeping genes for quantitative expression studies in the three-spined stickleback Gasterosteus aculeatus. BMC Mol Biol 2008, 9:18.

9. Ahn K, Huh J-W, Park S-J, Kim D-S, Ha H-S, Kim Y-J, Lee JR, Chang K-T, Kim H-S: Selection of internal reference genes for SYBR green qRT-PCR studies of rhesus monkey (Macaca mulatta) tissues. BMC Mol Biol 2008, 9:78.

10. Huggett J, Dheda K, Bustin S, Zumla A: Real-time RT-PCR normalisation; strategies and considerations. Genes Immun 2005, 6:279-284

II. Livak KJ, Schmittgen TD: Analysis of Relative Gene Expression Data Using Real-Time Quantitative PCR and the $2^{-\Delta \Delta} \mathbf{C t}$ Method. Methods 200I, 25:402-408.

12. Lindbjerg Andersen C, Jensen JL, Ørntoft TF: Normalization of Real-Time Quantitative Reverse Transcription-PCR Data: A Model-Based Variance Estimation Approach to Identify Genes Suited for Normalization, Applied to Bladder and Colon Cancer Data Sets. Cancer Res 2004, 64:5245-5250.

13. Kubista M, Andrade JM, Bengtsson M, Forootan A, Jonák J, Lind K, Sindelka R, Sjöback R, Sjögreen B, Strömbom L, et al.: The real-time polymerase chain reaction. Mol Asp Med 2006, 27:95-I25.

14. Pfaffl MW, Tichopad A, Prgomet C, Neuvians T: Determination of stable housekeeping genes, differentially regulated target genes and sample integrity: BestKeeper -Excel-based tool using pair-wise correlations. Biotechnol Lett 2004, 26:509-5I5.

15. Szabo A, Perou CM, Karaca M, Perreard L, Quackenbush JF, Bernard PS: Statistical modeling for selecting housekeeper genes. Genome Biol 2004, 5:R59.

16. Bustin S: Real-time, flourescence-based quantitative PCR: a snapshot of current procedures and preferences. Expert Review of Molecular Diagnostics 2005, 5(4):493-498.

17. Lefever S, Vandesompele J, Speleman F, Pattyn F: RTPrimerDB: the portal for real-time PCR primers and probes. Nucl Acids Res 2008:D942-5.

18. Feder ME, Mitchell-Olds T: Evolutionary and ecological functional genomics. Nat Rev Genet 2003, 4(8):649-655.

19. Michaux JR, Chevret P, Filippucci MG, Macholan M: Phylogeny of the genus Apodemus with a special emphasis on the subgenus Sylvaemus using the nuclear IRBP gene and two mitochondrial markers: Cytochrome $b$ and I2S rRNA. Mol Phylogenet Evol 2002, 23(2): $123-136$.

20. Meyer-Lucht Y, Sommer S: MHC diversity and the association to nematode parasitism in the yellow-necked mouse (Apodemus flavicollis). Mol Ecol 2005, 14:2233-2243.

21. Musolf K, Meyer-Lucht $Y$, Sommer S: Evolution of MHC-DRB class II polymorphism in the genus Apodemus and a comparism of DRB sequences within the family Muridae (Mammalia: Rodentia). Immunogenetics 2004, 56:420-426.

22. Horváth G, Wagner Z: Effect of densities of two coexistent small mammal populations on the survival of Apodemus flavicollis in a forest habitat. TISCIA (Szeged) 2003, 34:4I-46.

23. Miklós $P$, Žiak D: Microhabitat selection by three small mammal species in oak-elm forest. Folia Zool 2002, 5 I (4):275-288.

24. Ferrari N, Cattadori IM, Nespereira J, Rizzoli A, Hudson PJ: The role of host sex in parasite dynamics: field experiments on the yellow-necked mouse Apodemus flavicollis. Ecol Lett 2003, 6: I-7.

25. Klimpel S, Förster M, Schmahl G: Parasites of two abundant sympatric rodent species in relation to host phylogeny and ecology. Parasitol Res 2007, 100:867-875.

26. Nygard A-B, Jørgensen CB, Cirera S, Fredholm M: Selection of reference genes for gene expression studies in pig tissues using SYBR green qPCR. BMC Mol Biol 2007, 8:67.

27. Bogaert L, Van Poucke M, De Baere C, Peelman L, Gasthuys F, Martens A: Selection of a set of reliable reference genes for quantitative real-time PCR in normal equine skin and in equine sarcoids. BMC Biotechnol 2006, 6:24.

28. Tatsumi K, Ohashi K, Taminishi S, Okano T, Yoshioka M, Shima M: Reference gene selection for real-time RT-PCR in regenerating mouse livers. Biochem Biophys Res Commun 2008, 374: I 06-I I 0.

29. Bustin SA, Nolan T: Pitfalls of Quantitative Real-Time ReverseTranscription Polymerase Chain Reaction. J Biomol Tech 2004, 15:155-166.

30. Bustin SA: Quantification of mRNA using real-time reverse transcription PCR (RT-PCR): trends and problems. J Mol Endocrinol 2002, 29(I):23-39.

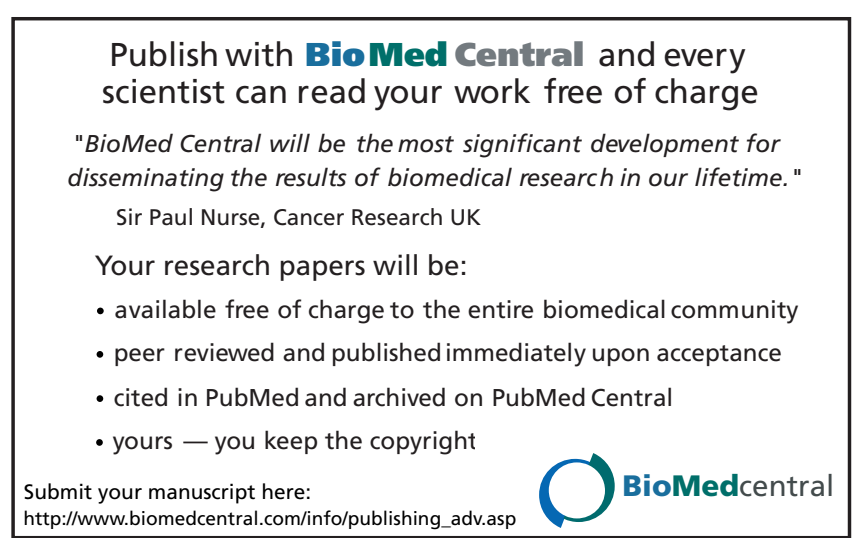

